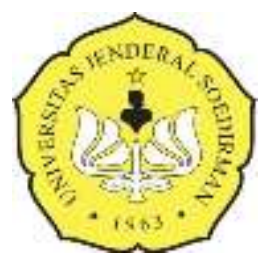

PAJU Volume 1 Nomor 12019

PHYSICAL ACTIVITY JOURNAL

http://jos.unsoed.ac.id/index.php/paju

\title{
Pengaruh Permainan Tradisional Banyumas Gol-Golan Terhadap Tingkat Kebugaran Jasmani Siswa Sekolah Dasar Di Kabupaten Banyumas
}

\author{
Kusnandar ${ }^{1}$, Dyah Umiarni Purnamasari², Panuwun Joko Nurcahyo ${ }^{3}$, Endo darjito 4 \\ 1,2,3,4 Fakultas IImu-IImu Kesehatan, Universitas Jenderal Soedirman, Indonesia \\ email: kusnandarunsoed@gmail.com 1 \\ DOI: https://doi.org/10.20884/1.paju.2019.1.1.1996
}

\begin{abstract}
Abstrak
Penelitian ini bertujuan untuk mengetahui pengaruh permainan tradisional Banyumas gol-golan terhadap tingkat kebugaran jasmani siswa Sekolah Dasar di Kabupaten Banyumas. Penelitian ini menggunakan desain penelitian eksperimen semu (quasi experiment) dengan menggunakan model one group pretest posttest design, yaitu eksperimen yang dilaksanakan pada satu kelompok, tanpa kelompok pembanding. Subjek pada penelitian ini adalah siswa kelas V SD N 1 Limpakuwus Kecamatan Sumbang Kabupaten Banyumas sebanyak 40 siswa. Data hasil penelitian diolah dengan menggunakan tabel nilai dan norma TKJI untuk anak usia 10-12 tahun. Untuk mengetahui pengaruh permainan yang diujikan, maka data hasil penelitian yang sudah diolah diuji dengan menggunakan uji statistik paired $t$ test. Hasil penelitian menunjukkan bahwa terdapat pengaruh permainan tradisional Banyumas gol-golan terhadap tingkat kebugaran jasmani siswa Sekolah Dasar di Kabupaten Banyumas, dengan taraf signifikansi 5\%
\end{abstract}

Kata Kunci: Permainan tradisional gol-golan, kebugaran jasmani.

\begin{abstract}
This study aims to determine the effect of traditional game Banyumas gol-golan against physical fitness level of elementary school students in Banyumas regency. This research used quasi experiment research design using one group pretest posttest design model, that is experiment conducted in one group, without comparison group. Subjects in this study were students of grade V SD N 1 Limpakuwus District Sumbang Banyumas Regency as many as 40 students. Data of research result is processed by using TKJI value table and norm for children aged 10-12 years. To know the influence of the game being tested, then the data of the research that has been processed is tested by using paired t test statistic. The results showed that there is an influence of traditional game of Banyumas gol-golan to physical fitness level of elementary school student in Banyumas Regency, with significance level 5\%
\end{abstract}

Keywords: Traditional game gol-golan, physical fitness.

\begin{tabular}{|c|c|c|c|}
\hline Alamat Koresponden & : $\quad$ Prodi PJKR Fakultas Ilu-Ilmu Kesehatan Unsoed & $\begin{array}{l}\text { e-ISSN } \\
\text { p-ISSN }\end{array}$ & $\begin{array}{l}: 2686-5807 \\
: 2686-5793\end{array}$ \\
\hline $\begin{array}{l}\text { E-mail } \\
\text { No. Telp./Hp }\end{array}$ & $\begin{array}{l}\text { : kusnandarunsoed@gmail.com } \\
:\end{array}$ & & \\
\hline
\end{tabular}




\section{PENDAHULUAN}

Pendidikan jasmani di sekolah merupakan bagian dari seluruh proses pendidikan yang mempunyai peranan penting dalam mencapai tujuan pendidikan. Oleh karena itu, tujuan pendidikan jasmani bersifat mendidik. Dalam pelaksanaannya, pendidikan jasmani dipakai sebagai wahana atau pengalaman belajar, dan melalui pengalaman tersebut peserta didik tumbuh dan berkembang untuk mencapai tujuan pendidikan. Dengan kata lain, pendidikan jasmani adalah proses belajar melalui aktifitas jasmani dan sekaligus sebagai proses belajar untuk menguasai kebugaran jasmani (Lutan, 2000).

(DEPDIKNAS, 2003) menyatakan bahwa pendidikan jasmani adalah suatu proses pembelajaran yang didesain untuk meningkatkan kebugaran jasmani, mengembangkan keterampilan motorik, pengetahuan dan perilaku hidup aktif, dan sikap sportif melalui kegiatan jasmani. Sedangkan menurut (Abdoellah \& Manaji, 1994) pendidikan jasmani perlu diberikan dilembaga pendidikan, karena aktivitas jasmani yang berbentuk latihan memberikan manfaat bagi peserta didik dalam bentuk kesegaran jasmani dan pemeliharaan kesehatan.

Permainan tradisional sebagai aset budaya bangsa perlu dilestarikan, digali dan ditumbuh kembangkan. Karena selain merupakan permainan juga mempunyai potensi untuk dapat lebih dikembangkan sebagai olahraga yang bisa membantu meningkatkan kualitas jasmani bagi pelakunya. Berbagai jenis permainan tradisional banyak kita miliki yang merupakan keanekaragaman budaya bangsa. Agar keanekaragaman permainan tradisional ini tetap menjadi Bhineka Tunggal Ika, perlu adanya dukungan dari pemerintah pusat, masyarakat, serta lingkungan. Pemerintah sudah memfasilitasi kegiatan permainan tradisional dan sudah dilakukan standarisasi tentang aturan permainan tradisional. Apabila anak-anak sejak kecil di lingkungan masyarakat sering bermain permainan tradisional akan berpengaruh terhadap perkembangan permainan tradisional dan permainan ini menjadi lebih dikenal, serta tertanam di benak anak-anak yang akan menjadi bekal dalam kehidupan dimasa yang akan datang.

Badan sehat dan bugar, tentu menjadi idaman setiap orang. Namun tidak setiap orang benarbenar mengetahui kebugarannya sebelum dilakukan tes dengan tes kebugaran. (Budi, 2015) menjelaskan bahwa Kebugaran jasmani merupakan aspek penting dari domain psikomotorik, yang bertumpu pada perkembangan kemampuan biologis organ tubuh. Kebugaran jasmani yang baik merupakan modal utama bagi seseorang untuk melakukan aktifitas fisik secara berulang dalam waktu yang relatif lama tanpa menimbulkan kelelahan yang berarti. Hasil penelitian (Purnamasari, Dardjito, \& Kusnandar, 2016) menunjukkan bahwa ada korelasi tingkat kesegaran jasmani dengan taraf inteligensi ( $p$ value: 0,024). Oleh karena itu, perlu dilakukan upaya-upaya terhadap peningkatan kebugaran jasmani siswa, khususnya siswa di sekolah dasar. (Budi, 2015) menjelaskan bahwa siswa dapat melakukan berbagai aktivitas belajar di sekolah maupun di masyarakat apabila mereka memilik kondisi tubuh dan kebugaran yang baik, sehingga dalam proses belajarnya siswa dapat mengembangkan potensi yang ada pada dirinya 
Kesadaran akan tingkat kebugaran jasmani siswa oleh guru Penjasorkes saat ini belum begitu diperhatikan. Padahal tes kebugaran jasmani sangat penting untuk dilakukan untuk mengetahui mengukur bugar atau tidaknya kondisi fisik peserta didik. Kebugaran jasmani yang optimal dapat diperoleh melalui latihan fisik yang benar, teratur, dan terukur. Apabila kita melakukan sesuatu kegiatan yang tidak berat dan fisik terasa sangat letih, maka bisa jadi kita memang kurang bugar. Dengan demikian, perlu dilakukan tes untuk mengukur kebugaran jasmani siswa, yang dapat dilakukan sebulan sekali atau setiap awal semester. Dengan melakukan tes kebugaran sebagai evaluasi atau peningkatan proses pembelajaran, dan sekaligus guru dapat memantau kebugaraan jasmani siswa pada umumnya.

Permainan tradisisonal merupakan salah satu aktivitas permainan yang memberikan kesenangan pada seseorang yang melakukan aktivitas permainan tersebut, terutama yang memiliki jasmani dan rohani yang sehat. Permainan tradisional merupakan permainan yang mengandung suatu gerak atau aktivitas jasmani, dimana anak akan melakukannya dengan sungguh-sungguh tanpa merasa lelah, sehingga akan berpengaruh terhadap pertumbuhan dan perkembangan jasmani anak. Permainan tradisional yang ada di daerah-daerah di Indonesia memiliki hubungan yang erat dengan adat istiadat dan tata krama dari pandangan hidup manusia. Oleh karena itu, permainan tradisional hendaknya disebarluaskan agar dikenal dan dimainkan oleh anak-anak Indonesia, serta digunakan sebagai media pembelajaran dalam pendidikan. Ciri-ciri permainan tradisional, amtara lain: alat yang digunakan sangat sederhana, belum terdapat peraturan yang pasti, dan tidak banyak mengeluarkan biaya. Ada beberapa permainan tradisional yang sudah dibakukan antara lain: egrang, gebug bantal, terompah panjang, lari balok, tarik tambang, hadang, patok lele, benteng, dagongan, sumpitan, gasing.

Permainan tradisional Banyumas Gol-Golan merupakan salah satu aktivitas permainan yang memberikan kesenangan pada seseorang yang melakukan aktivitas permainan tersebut, terutama yang memiliki jasmani dan rohani yang sehat. Permainan tradisional merupakan permainan yang mengandung suatu gerak atau aktivitas jasmani, dimana anak akan melakukannya dengan sungguh-sungguh tanpa merasa lelah, sehingga akan berpengaruh terhadap pertumbuhan dan perkembangan jasmani anak.

Siswa SD membutuhkan kebugaran jasmani yang baik agar mampu belajar secara optimal, sehingga mampu mencapai tujuan pembelajaran secara maksimal. Oleh karena itu, penelitian ini bertujuan memberikan dasar ilmiah untuk pemanfaatan permainan tradisional Banyumas Gol-Golan Sebagai Materi Pembelajaran Penjas di Sekolah Dasar di Kabupaten Banyumas.

\section{METODE}

Penelitian ini adalah penelitian eksperimen dengan menggunakan model one group pretest posttest design, yaitu eksperimen yang dilaksanakan pada satu kelompok saja tanpa kelompok pembanding (Sugiyono, 2015). Pada penelitian ini seluruh orang coba diberikan tes awal untuk 
Kusnandar ${ }^{1}$, Dyah Umiarni Purnamasari2, Panuwun Joko Nurcahyo ${ }^{3}$, Endo darjito ${ }^{4}$ PAJU : Physical Activity Journal 1 (1) (2019)

mengetahui kebugaran jasmani awal, kemudian diberikan perlakuan (treatment) berupa permainan tradisional gol-golan secara rutin yang dilakukan 3 kali/minggu selama 4 minggu (12 kali pertemuan), dan selanjutnya diadakan tes akhir untuk mengetahui kebugaran jasmani akhir.

Subjek pada penelitian ini adalah yaitu siswa kelas V SD N 1 Limpakuwus Kecamatan Sumbang Kabupaten Banyumas sebanyak 40 siswa. Menurut (Arikunto, 2009) apabila subjeknya kurang dari 100 orang, maka sebaiknya semua subjek diambil semua, sehingga penelitian tersebut merupakan penelitian populasi. Dengan demikian, penulis melakukan penelitian populasi, karena jumlah siswa dijadikan sebagai sampel penelitian sebanyak 40 siswa. Penelitian ini dilaksanakan di SD N 1 Limpakuwus.

Instrument dalam penelitian ini menggunakan Tes Kebugaran Jasmani Indonesia (TKJI) dari (Kementerian Pendidikan Nasional, 2010), untuk anak usia 10-12 tahun dengan nilai reliabilitas untuk putra 0,809 (AITKEN), sedangkan nilai validitas tes ini untuk putri 0,923 (AITKEN). Teknik pengumpulan data yang digunakan dalam penelitian ini menggunakan TKJI untuk anak usia 10-12 tahun. Pengumpulan data dilakukan dengan langkah-langkah: tes awal (pretest), pemberian perlakuan, dan tes akhir (posttest). Data yang diperoleh dikumpulkan, disusun dan dianalisis dengan langkah-langkah sebagai berikut:

\section{Tabel Nilai Kebugaram Jasmani dan Tabel Norma}

Penilaian kebugaran jasmani yang telah dilakukan kemudian dinilai menggunakan tabel nilai (untuk prestasi masing-masing butir tes)

Tabel 1. Nilai Tes Kesegaran Jasmani Indonesia Untuk Anak Usia 10-12 Tahun Putra.

\begin{tabular}{ccccccc}
\hline Nilai & $\begin{array}{c}\text { Lari } 40 \\
\text { Meter }\end{array}$ & $\begin{array}{c}\text { Gantung } \\
\text { Siku } \\
\text { Tekuk }\end{array}$ & $\begin{array}{c}\text { Baring Duduk } \\
\text { 30 dtk }\end{array}$ & $\begin{array}{c}\text { Loncat } \\
\text { Tecak }\end{array}$ & $\begin{array}{c}\text { Lari } 600 \\
\text { Meter }\end{array}$ & Nilai \\
\hline 5 & s/d 6.3 detik & 51 detik keatas & 23 keatas & $46 \mathrm{~cm}$ keatas & Sd 2'09" & 5 \\
\hline 4 & $6.4-6.9$ detik & $31-51$ detik & $18-22$ kali & $38-45 \mathrm{~cm}$ & $2^{\prime} 10^{\prime \prime}-2^{\prime 2} 30^{\prime \prime}$ & 4 \\
\hline 3 & $7.0-7.7$ detik & $15-30$ detik & $12-17$ kali & $31-37 \mathrm{~cm}$ & $2^{\prime 2} 31^{\prime \prime}-2^{\prime} 45^{\prime \prime}$ & 3 \\
\hline 2 & $7.8-8.8$ detik & $05-14$ detik & $04-11$ kali & $24-30 \mathrm{~cm}$ & $2^{\prime} 46^{\prime \prime}-3^{\prime} 44^{\prime \prime}$ & 2 \\
\hline 1 & $8.9-$ dst & $00-04$ detik & $00-03$ kali & Dibawah 24 cm & Sd 2'09" & 1 \\
\hline
\end{tabular}

Tabel 2. Nilai Tes Kesegaran Jasmani Indonesia Untuk Anak Usia 10-12 Tahun Putri.

\begin{tabular}{ccccccc}
\hline Nilai & $\begin{array}{c}\text { Lari } 40 \\
\text { Meter }\end{array}$ & $\begin{array}{c}\text { Gantung } \\
\text { Siku } \\
\text { Tekuk }\end{array}$ & $\begin{array}{c}\text { Baring Duduk } \\
30 \text { dtk }\end{array}$ & $\begin{array}{c}\text { Loncat } \\
\text { Tecak }\end{array}$ & $\begin{array}{c}\text { Lari } 600 \\
\text { Meter }\end{array}$ & Nilai \\
\hline 5 & s/d 6.7 detik & 40 detik keatas & 20 keatas & 42 cm keatas & Sd 2'32" & 5 \\
\hline 4 & $6.8-7.5$ detik & $20-39$ detik & $14-19$ kali & $34-41 \mathrm{~cm}$ & 2 '33"-2'54" & 4 \\
\hline 3 & $7.6-8.3$ detik & $08-19$ detik & $07-13$ kali & $28-33 \mathrm{~cm}$ & 2 '55"-3'28" & 3 \\
\hline 2 & $8.4-9.6$ detik & $02-07$ detik & $02-06$ kali & $21-27 \mathrm{~cm}$ & 3 '29"-4'22" & 2 \\
\hline 1 & $9.7-$ dst & $00-01$ detik & $00-01$ kali & Dibawah 21 cm Dibawah 4'22" & 1 \\
\hline
\end{tabular}

Setelah dilakukan tes kemudian untuk mengkalifikasikan TKJI anak usia 10-12 tahun yang telah mengikuti tes, maka dipergunakan norma seperti berikut: 
Tabel 3. Norma Tes Kesegaran Jasmani Indonesia

\begin{tabular}{ccc}
\hline No. & Jumlah Nilai & Klasifikasi \\
\hline 1 & $22-25$ & Baik Sekali (BS) \\
\hline 2 & $18-21$ & Baik (B) \\
\hline 3 & $14-17$ & Sedang (S) \\
\hline 4 & $10-13$ & Kurang (K) \\
\hline 5 & $05-09$ & Kurang Sekali (KS) \\
\hline
\end{tabular}

\section{Pengujian persyaratan analisis data}

Sebelum analisis data dilakukan uji persyaratan analisis, yaitu uji normalitas dan uji homogenitas data.

a. Uji normalitas

Untuk mencari kenormalan data penelitian, menurut Sutrisno Hadi (2004: 283) menggunakan metode chi-kuadrat, dengan rumus sebagai berikut:

$$
x^{2}=\sum \frac{(f o-f h)^{2}}{f h}
$$

Keterangan:

$x^{2}=$ nilai chi - kuadrat

fo $=$ frekuensi data yang diperoleh

$\mathrm{fh}=$ frekuensi yang diharapkan

b. Uji homogenitas data

Uji homogrnitas dilakukan dengan cara membagi varian yang lebih besar dengan varian yang lebih kecil (Sutrisno Hadi, 2004: 312).

$$
\text { F dbvb: dbvk }=\frac{\mathrm{SD}^{2} \mathrm{bs}}{\mathrm{SD}^{2} \mathrm{kt}}
$$

\section{Keterangan}

$\mathrm{Db} v \mathrm{vb}=$ derajat kebebasan dari varian yang lebih besar

$\mathrm{Db} v \mathrm{k}=$ derajat kebebasan dari variasi yang lebih kecil

$S D^{2}$ bs = varian yang lebih besar

$S D^{2} \mathrm{kt}=$ varian yang lebih kecil

\section{Uji t-tes}

Analisis perbedaan pada penelitian ini dengan langkah-langkah analisis data menurut Suharsimi (Arikunto, 2009) sebagai berikut:

a. Mencari rata-rata nilai tes awal $\left(0_{1}\right)$

b. Mencari rata-rata nilai tes akhir $\left(0_{1}\right)$

c. Menghitung perbedaan rata- rata dengan uji-t yang rumusnya adalah sebagai berikut: 


$$
t=\frac{\bar{D}}{\sqrt{\sum D^{2}-\frac{\left(\sum D\right)^{2}}{\frac{N}{N(N-1)}}}}
$$

Keterangan:

$\mathrm{T}=$ harga $\mathrm{t}$ untuk sampel berkorelasi

$D=$ (difference), perubahan antara skor tes awal dengan tes akhir untuk setiap individu

$\mathrm{D}=$ rerata nilai perbedaan (rerata dari $\mathrm{D}$ )

$D^{2}=\quad$ kuadrat dari $D$

$\mathrm{N}=$ banyaknya subjek penelitian

Derajat kebebasan (d.b) untuk pengguna rumus ini adalah (N-1).

HASIL

Data yang dikumpulkan dan dianalisis adalah data hasil tes kebugaran jasmani siswa, dengan menggunakan tes TKJI Tes Kebugaran Jasmani Indonesia. Untuk dapat mengetahui pengaruh permainan tradisional Banyumas gol-golan terhadap tingkat kebugaran jasmani siswa Sekolah Dasar di Kabupaten Banyumas akan diuji sesuai dengan hipotesis penelitian. Adapun data yang akan diuji adalah data pretest dan data post test. Deskripsi data akan dikategorikan seuai dengan kategori dalam TKJI. Berikut deskripsi data berdasarkan kelompok pretest dan post test.

Hasil pretest diperoleh skor dengan nilai minimum 7 dan nilai maksimum 18. Selanjutnya menyusun distribusi frekuensi berdasarkan kategori dalam TKJI. Berikut tabel distribusi frekuensi data kelompok pretest yang diperoleh.

Tabel 4 Distribusi Frekuensi TKJI Kelompok Pretest

\begin{tabular}{cccc}
\hline Kelas Interval & Kategori & Frekuensi & Frekuensi Komulatif \\
\hline $22-25$ & Baik Sekali & 0 & 0 \\
\hline $18-21$ & Baik & 1 & 1 \\
\hline $14-17$ & Sedang & 21 & 22 \\
\hline $10-13$ & Kurang & 14 & 36 \\
\hline $05-09$ & Kurang Sekali & 4 & 40 \\
\hline & Jumlah & & 40 \\
\hline
\end{tabular}

Dijelaskan pada tabel bahwa tidak ada siswa berkategori baik sekali, sebanyak 1 siswa berkategori baik, sebanyak 21 siswa berkategori sedang, sebanyak 14 siswa berkategori kurang, dan sebanyak 4 siswa berkategori kurang sekali. Hasil Post Test diperoleh skor dengan nilai minimum 11 dan nilai maksimum 23. Selanjutnya menyusun distribusi frekuensi berdasarkan kategori dalam TKJI. Berikut tabel distribusi frekuensi data kelompok post test yang diperoleh. 
Tabel 5. Distribusi Frekuensi TKJI Kelompok Post test.

\begin{tabular}{cccc}
\hline Kelas Interval & Kategori & Frekuensi & Frekuensi Komulatif \\
\hline $22-25$ & Baik Sekali & 5 & 5 \\
\hline $18-21$ & Baik & 10 & 15 \\
\hline $14-17$ & Sedang & 17 & 32 \\
\hline $10-13$ & Kurang & 8 & 40 \\
\hline $05-09$ & Kurang Sekali & 0 & 40 \\
\hline & Jumlah & 40 &
\end{tabular}

Dijelaskan pada tabel bahwa sebanyak 5 siswa berkategori baik sekali, sebanyak 10 siswa berkategori baik, sebanyak 17 siswa berkategori sedang, sebanyak 8 siswa berkategori kurang, dan tidak ada siswa yang berkategori kurang sekali.

Sebelum dilakukan analisis statistik, terlebih dahulu dilakukan uji asumsi atau uji persyaratan analisis yang meliputi uji normalitas dan uji homogenitas. Hasil Uji Normalitas dan homogenitas menunjukkan bahwa data pretest dan posttest adalah normal $(\operatorname{sig}=0,05)$ dan homogen $(s i g=0,05)$.

Tabel 6 Hasil perhitungan uji normalitas

\begin{tabular}{cccc}
\hline No. & Variabel & Asymp.Sig & Kesimpulan \\
\hline 1. & Pretest & 0,346 & Normal \\
\hline 2. & Post test & 0,957 & Normal \\
\hline
\end{tabular}

Tabel 7 Hasil Perhitungan Uji Homogenitas

\begin{tabular}{cccc}
\hline$F_{\text {hitung }}$ & $F(0,05)(1,78)$ & Sig. & Kesimpulan \\
\hline 3,151 & 8,49 & 0,080 & Homogen \\
\hline
\end{tabular}

Hasil analisis uji-t untuk mengetahui apakah terdapat pengaruh permainan tradisional Banyumas gol-golan terhadap tingkat kebugaran jasmani siswa Sekolah Dasar di Kabupaten Banyumas dapat dilihat pada tabel berikut.

Tabel 8 Rangkuman Hasil Analisis uji-t

\begin{tabular}{|c|c|c|c|c|}
\hline Perlakuan & $\mathbf{N}$ & Rerata & $\mathrm{T}_{\text {hitung }}$ & $\mathbf{T}_{\text {tabel }}$ \\
\hline Pretest & 40 & 2,69092 & $-9,112$ & 2,0227 \\
\hline Post Test & 40 & 3,43427 & & \\
\hline
\end{tabular}

Dari hasil tersebut dapat diketahui bahwa t hitung $=-9,112$ lebih besar dari $t_{(0,05)(39)}=2,0227$ pada taraf signifikansi $5 \%$. Dengan demikian hipotesis yang menyatakan terdapat pengaruh permainan tradisional Banyumas gol-golan terhadap tingkat kebugaran jasmani siswa Sekolah Dasar di Kabupaten Banyumas diterima. 


\section{PEMBAHASAN}

Permainan tradisional Banyumas gol-golan lebih dikenal secara umum dengan istilah bentengan. Gol-golan adalah permainan yang dimainkan oleh dua tim, masing-masing tim terdiri dari 4 atau lebih. Masing-masing tim memilih tempat sebagai markas, yang biasanya menggunakan tiang, batu atau pilar sebagai benteng. Di wilayah Banyumas biasanya menggunakan batu sebagai bentengnya.

Tujuan utama permainan gol-golan adalah untuk menyerang dan mengambil alih benteng lawan dengan menyentuh batu yang telah dipilih oleh lawan dan meneriakkan kata gol. Kemenangan juga bisa diraih dengan 'menawan' seluruh anggota lawan dengan menyentuh tubuh mereka. Untuk menentukan siapa yang berhak menjadi 'penawan' dan yang 'tertawan' ditentukan dari waktu terakhir saat si 'penawan' atau 'tertawan' menyentuh 'benteng' mereka masingmasing.

Permainan go-golan banyak mengandung unsur kebugaran jasmani, diantaranya unsur kecepatan, kelincahan, daya tahan, kekuatan, dan power. Menurut (Irianto, 2004) bahwa keberhasilan untuk mencapai kebugaran ditentukan oleh kualitas latihan, meliputi: tujuan latihan, pemilihan model latihan, sarana latihan dan dosis latihan konsep FIT (Frequency Intensity, and time). Frequency adalah unit latihan persatuan waktu, latihan 3-5 kali per minggu. Intensity adalah berat ringannya kualitas latihan, 75-85\% detak jantung maksimal (DJM), dihitung dengan cara 220-umur (dalam tahun). Time adalah durasi yang diperlukan setiap kali latihan, waktu berlatih 20-60 menit.

Permainan gol-golan yang dilatihkan kepada siswa memiliki dampak yang signifikan karena program latihan yang diberikan mampu memberikan pengaruh terhadap kebugaran siswa. Permainan golgolan jika dilaksanakan dengan menggunakan program latihan maka akan dapat untuk meningkatkan kebugaran jasmani siswa.

\section{KESIMPULAN}

Berdasarkan hasil penelitian yang telah diperoleh dengan analisis dan pengujian hipotesis, maka dapat ditarik kesimpulan terdapat pengaruh permainan tradisional Banyumas gol-golan terhadap tingkat kebugaran jasmani siswa Sekolah Dasar di Kabupaten Banyumas.

\section{REFERENSI}

Abdoellah, A., \& Manaji, A. (1994). Dasar-Dasar Pendidikan Jasmani. DEPDIKNAS.

Arikunto, S. (2009). Dasar-dasar evaluasi pendidikan. Jakarta: Bumi Aksara.

Budi, Didik Rilastiyo (2015) Pengaruh Modifikasi Permainan Vobas dan Kebugaran Jasmani Terhadap 
Kusnandar ${ }^{1}$, Dyah Umiarni Purnamasari2, Panuwun Joko Nurcahyo ${ }^{3}$, Endo darjito ${ }^{4}$ PAJU : Physical Activity Journal 1 (1) (2019)

Peningkatan Kerjasama Siswa Dalam Pembelajaran Penjas Di SMP. S2 thesis, Universitas Pendidikan Indonesia

DEPDIKNAS. (2003). Pedoman Khusus Pengembangan Silabus dan Penilaian (Pendidikan Jasmani). Jakarta: DEPDIKNAS.

Irianto, D. P. (2004). Pedoman Praktis Berolahraga untuk Kebugaran \& Kesehatan. Yogyakarta: Andi.

Kementerian Pendidikan Nasional. (2010). Panduan Pelaksanaan Tes Kesegaran Jasmani Indonesia. Jakarta: Pusat Pengembangan Kualitas Jasmani.

Lutan, R. (2000). Dasar-Dasar Kepelatihan. Depdiknas.

Purnamasari, D. U., Dardjito, E., \& Kusnandar. (2016). Hubungan Jumlah Anggota Keluarga, Pengetahuan Gizi lbu Dan Tingkat Konsumsi Energi Dengan Status Gizi Anak Sekolah Dasar. Kesmas Indonesia, 8 (2).

Sugiyono. (2015). Metodologi Penelitian Pendidikan. Bandung: CV. Alfabeta. 